\title{
Control of Refractory Hypercalcemia with Denosumab in a Case of Metastatic Parathyroid Carcinoma
}

\author{
Murat Çalapkulu ${ }^{1}$, Ozen Oz Gul², Soner Cander², Canan Ersoy², Erdinc Erturk², Muhammed Fatih Sagiroglu ${ }^{3}$ and \\ Ozlem Saraydaroglu ${ }^{4}$ \\ ${ }^{1}$ Department of Endocrinology and Metabolism, University of Health Sciences, Diskapi Yildirim Beyazit Training and Research Hospital, \\ Ankara, Turkey \\ ${ }^{2}$ Department of Endocrinology and Metabolism, Uludag University Medical School, Turkey \\ ${ }^{3}$ Department of Internal Medicine, Uludag University Medical School, Turkey \\ ${ }^{4}$ Department of Pathology, Uludag University Medical School, Turkey
}

\begin{abstract}
Parathyroid carcinoma is a rare cause of hyperparathyroidism and leads to severe hypercalcemia. The etiology is not fully known. Parathyroid cancer should be considered in the differential diagnosis, if serum calcium and parathyroid hormone levels increase, and parathyroid gland is palpable. Severe hypercalcemia is the most common cause of death in patients diagnosed with parathyroid carcinoma. Fluid replacement, diuretic therapy, bisphosphonates, and calcimimetic agents are the main treatment steps in the control of life-threatening hypercalcemia. Surgery is the primary treatment option, while denosumab is a treatment option for refractory hypercalcemia caused by parathyroid carcinoma, or for patients who are not eligible for surgery. There are few case reports in literature about denosumab treatment for parathyroid carcinoma. Herein, we report a case of a patient who presented with the complaint of leg pain and was diagnosed with parathyroid carcinoma. The elevated calcium level of the patient was controlled with denosumab.
\end{abstract}

Key Words: Parathyroid carcinoma, Denosumab, Hypercalcemia, Hyperparathyroidism.

How to cite this article: Çalapkulu M, Gul OO, Cander S, Ersoy C, Erturk E, Sagiroglu MF, Saraydaroglu O. Control of Refractory Hypercalcemia with Denosumab in a Case of Metastatic Parathyroid Carcinoma. J Coll Physicians Surg Pak 2020; 30(07):757-759.

\section{INTRODUCTION}

Parathyroid carcinoma is a rare tumorand constitutes $0.5-5 \%$ of primary hyperparathyroidism cases. ${ }^{1}$ Parathyroid cancer should be considered in the differential diagnosis, if serum calcium and parathyroid hormone levels increase, and palpable parathyroid gland is detected. ${ }^{1}$ Morbidity and mortality in parathyroid carcinoma cases are related to hypercalcemia due to parathormone (PTH) secreted by tumor cells rather than tumor size. ${ }^{2}$ The definitive treatment of the disease is surgery. ${ }^{3}$ In parathyroid carcinoma patients, the cause of death is usually uncontrolled hypercalcemia. ${ }^{2}$ However, life-threatening hypercalcemia can be controlled with fluid replacement, diuretic therapy, bisphosphonates, and calcimimetic agents.

Correspondence to: Murat Çalapkulu, Department of Endocrinology and Metabolism, University of Health Sciences, Diskapi Yildirim Beyazit Training and Research Hospital, Sehit Omer Halisdemir Avenue, 06110, Ankara, Turkey

E-mail: calapkulumurat89@gmail.com

Received: July 20, 2019; Revised: July 20, 2019;

Accepted: July 21, 2019

DOI: https://doi.org/10.29271/jcpsp.2020.07.757
Denosumab is a monoclonal antibody that binds to RANKL with a high affinity, disrupts RANKL-RANK interaction, and inhibits bone resorption. Denosumab is generally used in the treatment of postmenopausal osteoporosis and prevention of skeletal-related events in malignancies with bone metastases. ${ }^{4}$ Published studies of denosumab treatment in refractory and recurrent hypercalcemia, associated with parathyroid carcinoma, are limited to case reports. ${ }^{5,6}$ In the current case, we report a patient who presented with the complaint of leg pain, was determined to have multiple bone lesions, and was diagnosed with parathyroid carcinoma. The elevated calcium level of the patient was controlled with denosumab.

\section{CASE REPORT}

A 61-year male patient presented to our clinic with the complaint of widespread leg pain. No pathological findings were found in the physical examination. The laboratory test results revealed serum PTH of 2233 ng/L (Normal: 15-68.3), calcium 15.7 mg/dl (Normal: 8.4-10.2) 25-OH-D 9.7 $\mu \mathrm{g} / \mathrm{L}$, alkaline phosphatase (ALP) $532 \mathrm{lU} / \mathrm{ml}$ (Normal: 40-150), phosphorus $2.9 \mathrm{mg} / \mathrm{dl}$ (Normal: $2.3-4)$, and creatinine $1.99 \mathrm{mg} / \mathrm{dl}$ (Normal: 0.7-1.1). Multiple lytic lesions in the pelvis, cranium, and long-bones were observed on radiography. Neck ultrasonography showed a hypoechoic solid nodule with cystic areas, $2 \times 2 \mathrm{~cm}$ in size, in the left thyroid gland inferior region; and delayed washout was detected on parathyroid scintigraphy. Metastasis was suspected on bone scintigraphy. 
Table I: Serum calcium, parathyroid hormone, phosphorus, and creatinine levels after subcutaneous denosumumab therapy. Albumincorrected serum calcium concentrations in $\mathrm{mg} / \mathrm{dl}$ in our patient are depicted.

\begin{tabular}{|l|c|c|c|c|}
\hline A.T. Interval & Serum calcium & Serum phosphorus & Serum parathormoe & Serum creatinine \\
\hline B.T & $12.4 \mathrm{mg} / \mathrm{dl}$ & $1.8 \mathrm{mg} / \mathrm{dl}$ & $1549 \mathrm{ng} / \mathrm{L}$ & $1.41 \mathrm{mg} / \mathrm{dl}$ \\
\hline First month & $11 \mathrm{mg} / \mathrm{dl}$ & $1.7 \mathrm{mg} / \mathrm{dl}$ & $2682 \mathrm{ng} / \mathrm{L}$ & $1.47 \mathrm{mg} / \mathrm{dl}$ \\
\hline Third month & $10.7 \mathrm{mg} / \mathrm{dl}$ & $1.7 \mathrm{mg} / \mathrm{dl}$ & $2714 \mathrm{ng} / \mathrm{L}$ & $1.47 \mathrm{mg} / \mathrm{dl}$ \\
\hline Sixth month & $10.7 \mathrm{mg} / \mathrm{dl}$ & $1.8 \mathrm{mg} / \mathrm{dl}$ & $3773 \mathrm{ng} / \mathrm{L}$ & $1.37 \mathrm{mg} / \mathrm{dl}$ \\
\hline
\end{tabular}

A.T: After treatment, B.T: Before treatment (Reference range: Serum calcium 8.4-10.2 mg/dl, serum phosphorus 2.3-4 mg/dl, serum parathormone 15-68.3 Serum creatin:0.7-1.1 $\mathrm{mg} / \mathrm{dl}$ )

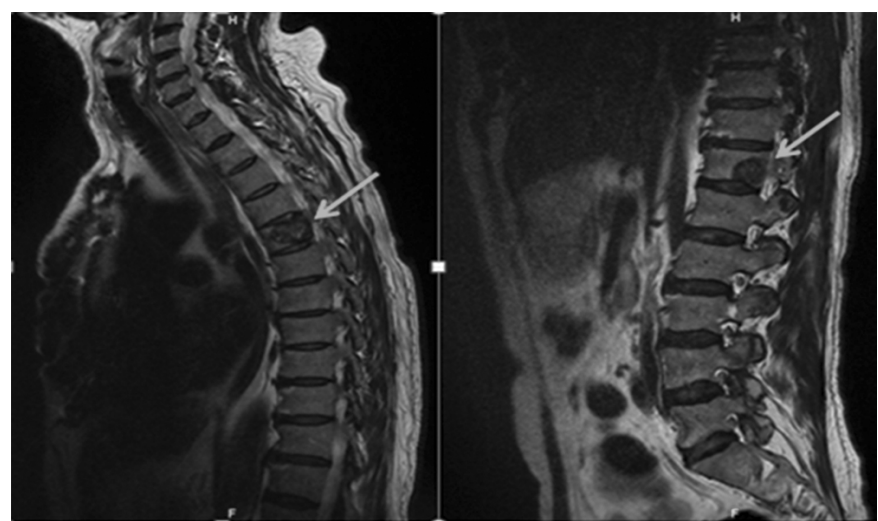

Figure 1: Sagittal MRI of spine metastases.

Neck, thoracic, and lumbar magnetic resonance imaging (MRI) showed lesions in the posterior part of vertebrae (Figure 1). Intravenous hydration and furosemide treatment was started with the addition of zoledronic acid infusion. Left hemithyroidectomy and parathyroidectomy were performed after the calcium level decreased to $12 \mathrm{mg} / \mathrm{dl}$. Pathology examination revealed parathyroid carcinoma of $20 \times 15 \mathrm{~mm}$, invading the thyroid gland. Thoracic computed tomography (CT) imaging revealed no metastasis in the lungs, but lytic lesions consistent with multiple metastases were detected in bone structures.

Six months after the operation, there were two lymphadenopathies $(10 \times 10 \mathrm{~mm})$ in the left cervical chain, and one atypical lymphadenopathy $(20 \times 10 \mathrm{~mm})$ in the right cervical chain. No new lesions were determined on thoracic CT and whole spine MRI. Biopsy of the atypical lymph node detected on the left side was determined as malignant infiltration. The patient was accepted as a recurrence. Left lateral neck dissection was performed for recurrence, and one metastatic lymph node was detected.

At 19 months postoperatively, a $9 \mathrm{~mm}$ nodule was detected in the mediobasal segment of the right lower lobe of the lung, and this was excised. Pathology results were consistent with parathyroid carcinoma metastasis. The patient's serum calcium level did not improve with monthly treatment of zoledronic acid. Cinacalcet was added to the treatment, but the calcium levels could not be controlled despite a dose of $90 \mathrm{mg} /$ day. The patient could not tolerate higher doses of cinacalcet because of side-effects. Therefore, denosumab therapy was added as a monthly administration of $120 \mathrm{mg}$ subcutaneously, while continuing a daily cinacalcet dose of $90 \mathrm{mg}$. After 6 months of denosumab treatment, the calcium levels decreased dramatically (Table I). Biochemical follow-up at 6-12 week interval and follow-up for distant metastases at 3-6 month interval was planned.

\section{DISCUSSION}

Denosumab is a monoclonal antibody, which has been shown to increase bone mineral density in postmenopausal women, to inhibit bone resorption and decrease hypercalcemia in hematological malignancies, and solid tumors with bone metastasis. ${ }^{1-3}$ There is no clinical study in literature that has evaluated the efficacy of denosumab in reducing calcium levels in patients with severe PTH excess due to parathyroid carcinoma. In some case reports about parathyroid carcinoma, denosumab monotherapy has been reported to control refractory hypercalcemia in patients who could not be controlled with surgery, bisphosphonate, calcimimetic, and dacarbazine treatments. ${ }^{5,6}$ Vellanki et al. used bisphosphonate, calcium receptor agonist, and chemotherapy (dacarbazine) treatments for a 39-year patient with metastatic parathyroid carcinoma. However, the serum calcium level could not be brought under control. With the addition of denosumab (120 mg once a month) to the treatment, the calcium level was successfully controlled for 16 months. ${ }^{5}$ In another case report by Tong et al., hypercalcemia, induced by metastatic parathyroid cancer, was resistant to standard treatment. Temporary hemodialysis was performed to control hypercalcemia, and subcutaneous calcitonin was also administered several times, but the calcium levels could not be controlled. Oral cinacalcet was initiated, but was not sufficient to control the calcium level. Subcutaneous denosumab of $120 \mathrm{mg} / \mathrm{month}$ was administered, and calcium levels rapidly normalised by the third day. ${ }^{6}$ In the current case, metastasis was detected in the lung at 19 months postoperatively and the calcium level was not brought under control with bisphosphonate and cinacalcet treatment. Therefore, denosumab was added 
to the patient's treatment, and the calcium levels were brought under control.

In conclusion, considering that parathyroid cancer-mediated hypercalcemia is a result of elevated PTH levels, a denosumab-induced decrease in calcium levels suggests that denosumab may prevent the hypercalcemic effect of PTH, and may also have a potential role in the palliative treatment of metastatic parathyroid cancer.

\section{PATIENT'S CONSENT:}

Participant were informed about the research protocol and he declared his voluntary attendance with assigned written assent.

\section{CONFLICT OF INTEREST:}

The authors declared no conflict of interest.

\section{AUTHORS' CONTRIBUTION:}

MC: Wrote the manuscript.

MC, OOG, SC: Participated in data collection.

MC, OS, MFS: Participated in figure collection.

MC, OOG, CE, EE: Contributed to the Discussion.
MC, OOG, CE, SC, EE: Contributed to study design, reviewed and edited the manuscript.

\section{REFERENCES}

1. Lee PK, Jarosek SL, Virnig BA, Evasovich M, Tuttle TM. Trends in the incidence and treatment of parathyroid cancer in the United States. Cancer 2007; 109(9): 1736-41.

2. Busaidy NL, Jimenez C, Habra MA, Schultz PN, El-Naggar AK, Clayman GL, et al. Parathyroid carcinoma: A 22-year experience. Head Neck 2004; 26(8):716-26.

3. Givi B, Shah JP. Parathyroid carcinoma. Clin Oncol R Coll Radiol G B 2010; 22(6):498-507.

4. Thosani S, Hu MI. Denosumab: A new agent in the management of hypercalcemia of malignancy. Future Oncol 2015; 11(21):2865-71.

5. Vellanki P, Lange K, Elaraj D, Kopp PA, El Muayed M. Denosumab for management of parathyroid carcinomamediated hypercalcemia. J Clin Endocrinol Metab 2014; 99(2):387-90.

6. Tong CV, Hussein Z, Noor NM, Mohamad M, Ng WF. Use of denosumab in parathyroid carcinoma with refractory hypercalcemia. QJM 2015; 108(1):49-50. 